\title{
La emergencia de los social media en la comunicación empresarial
}

Dra Estela Bernad Universitat Jaume I

La aparición de Internet ha supuesto un cambio vertiginoso en la comunicación y a la vez en el modo de relacionarse las personas, tanto en su aspecto personal como en su faceta laboral. A partir de su incorporación en nuestras vidas, se han ido generando diferentes herramientas de comunicación e intercambio de información que poco a poco han ido transformando el panorama actual produciendo un nuevo sistema comunicativo, integrado por la convergencia entre la industria de la comunicación y la cultura de masas, con la informática, las telecomunicaciones de uso cotidiano y la industria del conocimiento.

Este contexto variante, no ha sido ni es baladí al mundo empresarial, enfrentándose las corporaciones a nuevos retos en la concepción de su comunicación. Las nuevas tecnologías de la comunicación y los trepidantes cambios en la concepción de la misma han supuesto la incorporación de nuevas estrategias y herramientas ante un nuevo público con distinta aptitud en su recepción. Por otro lado, el panorama tremendamente competitivo se apoya cada día más en los valores e intangibles que inciden en la nota de distinción de los productos o servicios una vez llegado a unos niveles razonables de calidad. De esta manera una buena imagen de marca que posicione el producto ante los públicos objetivos es fundamental, ya que si las personas han modificado la forma de relacionarse, la percepción de las empresas está cada vez más en manos de los usuarios, las vías para llegar a ellos se han visto afectadas y, a su vez, están intentando adaptarse a las nuevas reglas de juego. Era apremiante un cambio, en las estrategias de comunicación de las empresas. 
En esta trama, la emergencia de los social media ha comportado ese cambio radical en la forma de comunicar de las empresas, originando nuevas dimensiones, el espectador antaño pasivo, se convierte en usuario interactuando con el medio. Esto ha supuesto una modificación en el esquema lineal, unidireccional y jerárquico de la comunicación tradicional que pasará a ser más democrática y bidireccional al permitir posibilidades de interactuación de los destinatarios/ consumidores de manera inmediata y así conseguir bien la adquisición del producto o más información sobre el mismo.

Las aportaciones que han realizado los distintos autores de esta sección dedicada a ser una tribuna abierta principalmente al mundo profesional, nos permiten observar cómo se abren ante nosotros nuevas oportunidades que se empiezan a intuir. Comenzando por un producto tradicional como el libro, Pedro Palao aporta desde su experiencia editorial, la necesaria inmersión de empresas y autores en estas nuevas estrategias de comunicación puesto que hoy en día un libro no acaba en la contraportada, sino que el público actual requiere de contenidos interactivos que prolonguen los contenidos e historias a través de las redes sociales, suponiendo que aquellas empresas o autores que no se adapten a estas demandas tendrán serios problemas en un mundo donde la competencia es feroz. Por otro lado, la experiencia de la utilización de los social media desde la dirección de la comunicación de Patricia Martínez, en una fundación con un objeto social tan específico como es la Fundación Atapuerca, nos demuestra cómo ha permitido socializar la ciencia antropológica, llegando a un gran público que se ha interesado por estos conocimientos científicos tan especiales gracias a la facilitación de los conceptos y la información a través de la interactividad. De la misma manera, Enric Sánchez, desde su experiencia en una agencia de comunicación creativa, considera que apostar por los social media es algo imprescindible que supone una gran ventaja para la empresa pues le aporta cercanía con su clientela y personalización en un mundo globalizado. Y por otro lado, Ricardo Beitia, incide en la necesidad de humanización de este tipo de comunicación, debiendo existir una implicación clara de la persona en pro de mayor calidad informativa y en este sentido apuesta por el compromiso de la ciencia de las Relaciones Públicas en su papel estratégico en la comunicación empresarial como mediadora entre las empresas y sus clientes.

Asimismo, esta sección se completa por los artículos reflexivos de expertos teóricos como la doctora Mut que apunta sobre la coherencia de la reputación corporativa online y la doctora Arda y el doctor Fernández que exploran sobre la importancia de la imagen de marca a través de las redes sociales. Finalmente, este apartado concluye con la reseña realizada por el maestro Joan Costa sobre la publicación de Francisco Fernández Beltrán: Comunicación interna 2.0. La gestión de portales corporativos y redes sociales. De esta manera, todas las aportaciones que se presentan en esta sección, nos permiten de una manera rápida, pero a la vez profunda, realizar una aproximación sobre la indiscutible importancia que tienen los social media en la comunicación corporativa hoy en día. 


\section{Referencia de este artículo:}

Bernad Monferrer, Estela (2012). La emergencia de los social media en la comunicación. En: adComunica. Revista Científica de Estrategias, Tendencias e Innovación en Comunicación, $\mathrm{n}^{0} 3$. Castellón: Asociación para el Desarrollo de la Comunicación adComunica, Universidad Complutense de Madrid y Universitat Jaume I, 211-213. DOI: http://dx.doi.org/10.6035/2174-0992.2012.3.13 